\title{
Pump impeller failures — a compendium of case studies
}

\author{
A. van Bennekom ${ }^{\mathrm{a}, *}$, F. Berndt ${ }^{\mathrm{b}}$, M.N. Rassool ${ }^{\mathrm{a}}$ \\ ${ }^{a}$ School of Process and Materials Engineering, University of the Witwatersrand, Private Bag 3, P.O. WITS 2050, South Africa \\ ${ }^{\mathrm{b}}$ Advanced Engineering and Testing Services, MATTEK, CSIR, Private Bag X28, Auckland Park 2006, South Africa
}

Received 10 June 1999; accepted 26 October 1999

\begin{abstract}
This paper presents a collection of pump impeller failures that have been encountered during the consulting activities at the University of the Witwatersrand and the Plant Infrastructure and Pipelines Centre at the Council for Scientific and Industrial Research. (C) 2001 Published by Elsevier Science Ltd.
\end{abstract}

Keywords: Casting defects; Cavitation failures; Coating failures; Impeller failures; Pump failures

\section{Introduction}

The pumping of fluids within a plant and between plants is integral to the economic functioning of any chemical or petrochemical industry. It is thus of utmost importance that premature failure of these pieces of equipment be avoided.

In addition to the pump problems that were experienced in the past, the woes of pump operators have been increased by some companies adopting a 'zero-effluent discharge policy'. Essentially this means that the effluent that is produced by a particular plant has to be retained and recycled within the plant rather than discarding the effluent into rivers or the environment. Unfortunately, the effluent becomes more contaminated with each recycle and as such several problems can be encountered with pumps and associated piping systems since many of these systems were simply not designed to handle such concentrated or contaminated solutions.

One of the best ways to avoid future failures is to examine the causes of failure in the past and to try and learn from past experience. Although pump failures may have many causes, this paper will only present case studies of impeller failures.

\footnotetext{
* Corresponding author. Tel.: +49(0) 217808 2207; fax: +49(0) 2718082501.

E-mail address: bennekom@kep.thyssenkrupp.com (A. van Bennekom).
} 


\section{Fragmentation of a 316 impeller due to a casting defect}

This CF-8M (cast equivalent of type 316 stainless steel) impeller, which was used to pump a nickel sulphate solution, fragmented after only a few hours in service. The failure of this impeller resulted in a significant financial loss due to subsequent damage and loss of production. On removal of the impeller, it was noted that some 'pitting' and slight cracking was evident along the interface between the web and flange of the impeller (see Fig. 1). The plant personnel assumed the failure to be due to pitting corrosion in the nickel sulphate solution, but this was obviously not the case since the previous impeller, which was also made from CF-8M stainless steel, operated for several years without pitting being observed. Also, pitting would not be expected to occur this rapidly.

When a portion of the impeller, which was sectioned through the cracked and pitted region, was prepared for metallographic examination by grinding and polishing a transverse section, extensive porosity was observed. The extent and location of this porosity is evident in the photograph in Fig. 2. From the location and morphology of the porosity it is clear that this defect has been caused by shrinkage porosity during solidification of the casting. Unfortunately, this defect is located in the most highly stressed portion of the impeller and it is thus not surprising that the impeller fragmented after only a short time in service.

When a metal solidifies from the molten state, in a casting for instance, the volume of the metal decreases and unless steps are taken to ensure that this shrinkage is compensated for by feeding the casting with more liquid metal, shrinkage porosity will result. The resultant shrinkage porosity is usually located at the last region to solidify and appears as an irregularly shaped cavity within the casting.

It can thus be seen that this failure was due to insufficient feeding of the casting with molten metal during the solidification process. This failure could have been avoided if additional runners and risers

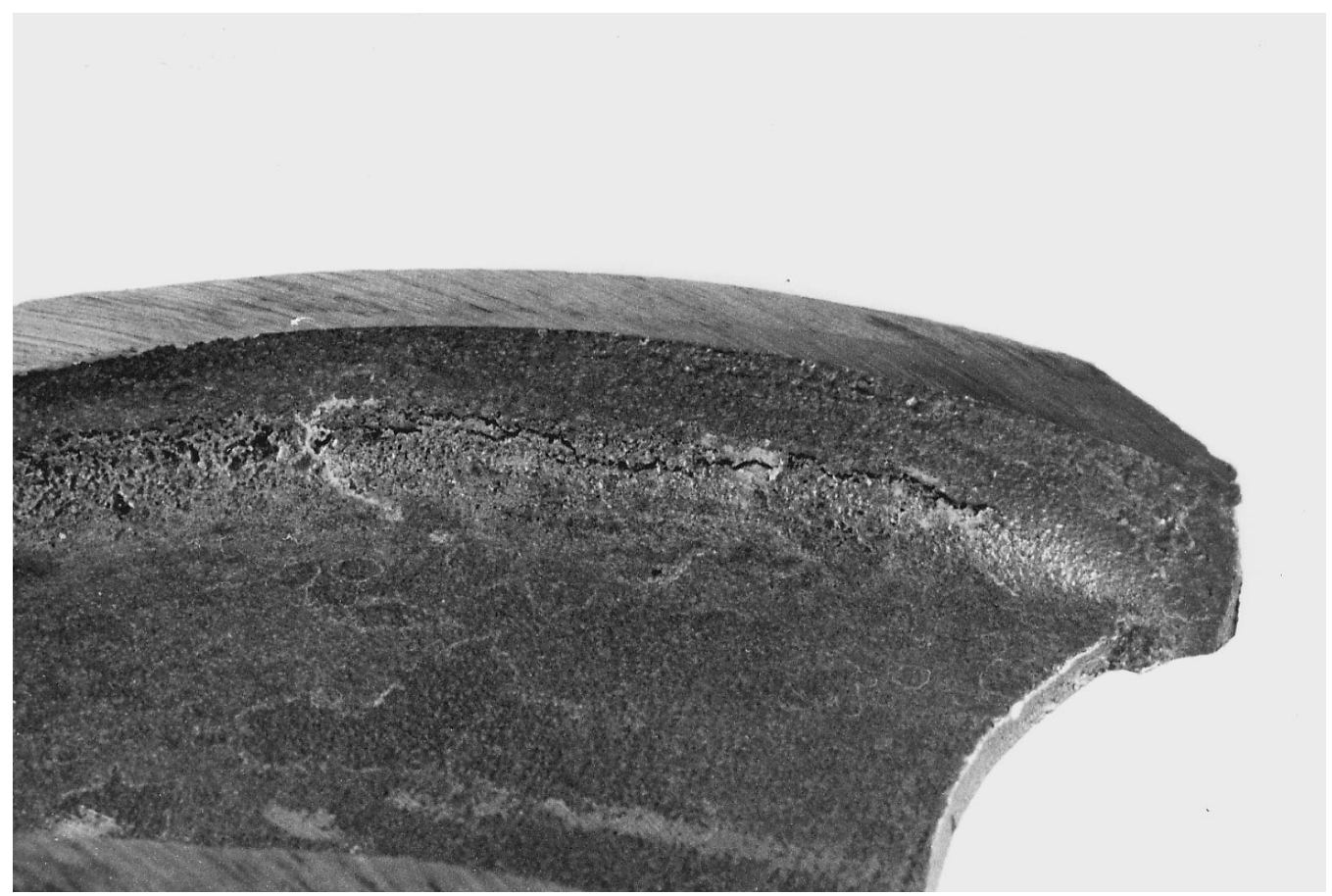

Fig. 1. 'Pitting' and cracking at the junction between web and flange of a cast 316 type stainless steel impeller. 
had been used in the casting. It is also evident that a lack of quality control at the foundry that cast this impeller allowed the impeller to be dispatched and subsequently be installed in the pump where it failed.

A similar failure was observed in a bronze impeller which also failed after a relatively short time in service. Examination of the fragments of this impeller showed that failure was due to the presence of porosity in the casting. In fact, the porosity that was present on the fracture surface was so pronounced (see Fig. 3), that it was not necessary to perform a microstructural examination to confirm the presence of extensive shrinkage porosity.

\section{Failure of a bronze impeller due to a casting defect}

A bronze impeller was installed in a pump, but on start-up a significant amount of vibration was observed followed by fragmentation of the impeller a few minutes later. When the fragments of the impeller were examined, a blue oxide layer was observed on some of the fracture surfaces, showing that the impeller in question had failed due to the presence of a pre-existing crack.

The presence of this blue oxide layer on the fracture surface shows that the crack must have formed during solidification of the casting since a glossy blue oxide of this type only forms at high temperatures (see Fig. 4). The intriguing part about this failure is that the defect, which measures at least $6 \mathrm{~cm}$ in length, was not detected by either the manufacturer or the technicians who installed the impeller. This failure thus shows us that pump impellers should be visually examined for defects before they are installed into a pump.

From these two case studies it can be seen that metallurgical defects result in very rapid failure and

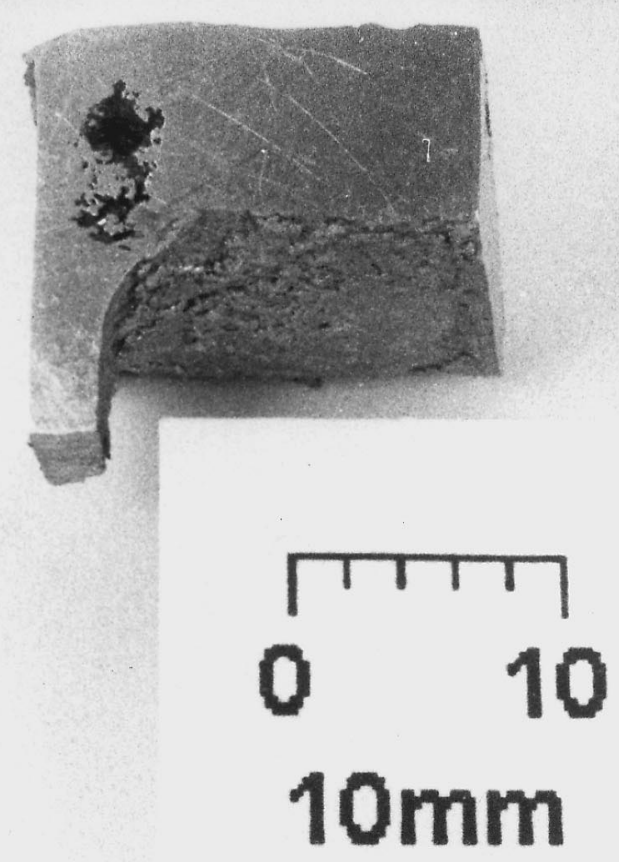

Fig. 2. Porosity on a cross section from the cracked region of Fig. 1. 
that the failures have very little to do with the operational conditions of the pump. Apart from performing a visual examination of the impeller before installation and ensuring that the supplier adheres to stringent quality control checks, there is very little that a pump operator can do to avoid failure as a result of the presence of metallurgical defects.

\section{Coating failure on an impeller wear ring}

This case study is concerned with the failure of a stellite coating on an impeller wear ring. The problem manifested itself when severe vibration was detected on a pump in which a new stainless steel impeller had just been installed. This vibration was found to become steadily worse until the pump was stopped. The impeller was removed to determine the cause of the vibration. On removal of the impeller, it was noted that the wear ring had suffered from extensive galling damage (see Fig. 5). Examination of the wear ring showed that it had been stellite-coated. The reason for coating the wear ring with a stellite coating is to prevent or minimise the amount of galling damage that would usually occur between two stainless steel surfaces. As a general rule the coating that is used should be at least 50-60 Brinell hardness units higher than the hardness of the stainless steel.

After visual examination of the failed wear ring, it was thought that the stellite coating had spalled off the stainless steel substrate due to inadequate surface preparation prior to thermal spraying of the stellite coating. When the wear ring was sectioned, and prepared for metallographic examination, it was noted that the interface between the coating and the stellite coating was intact and that failure had

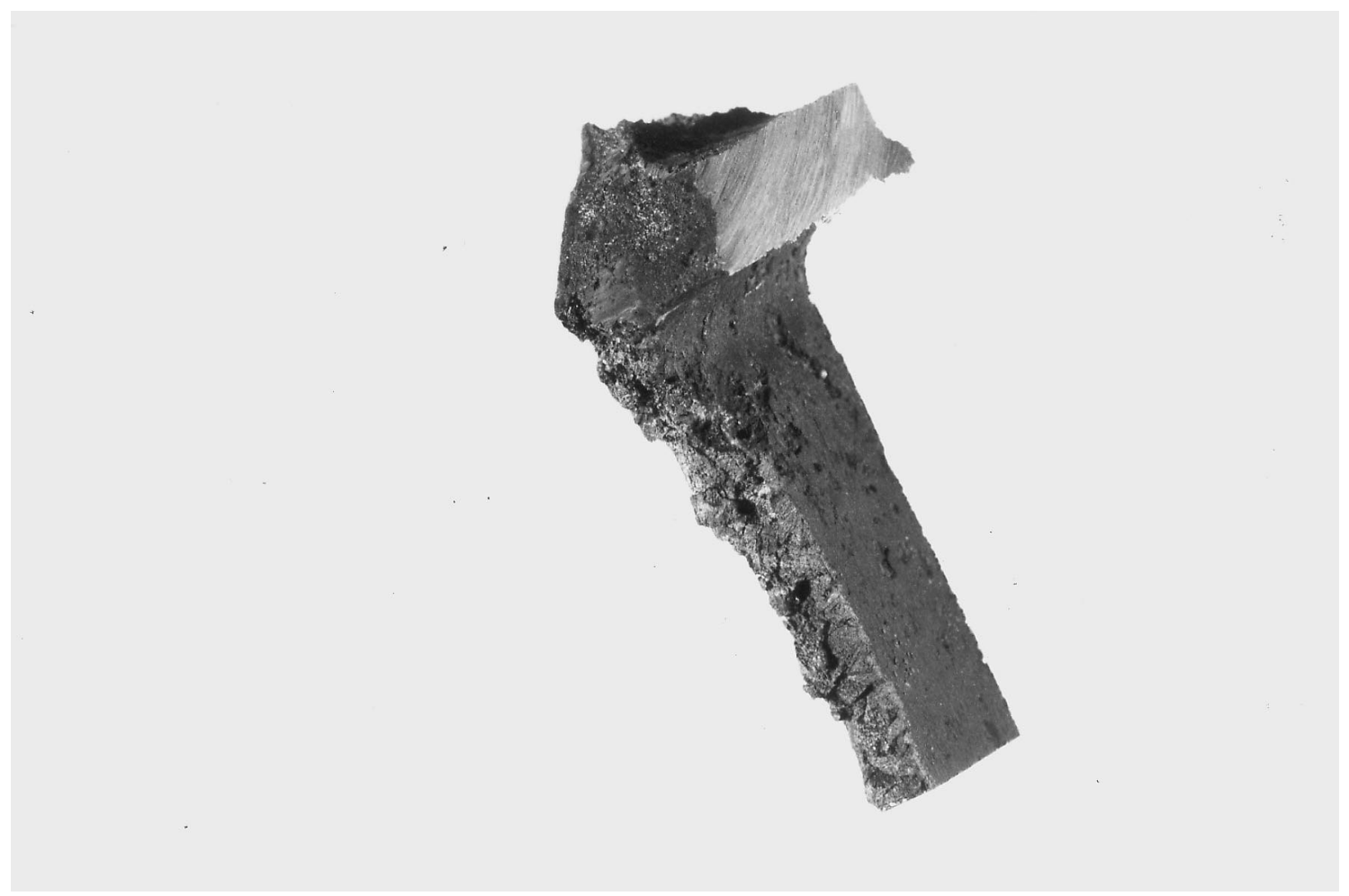

Fig. 3. Porosity in a failed bronze impeller. 


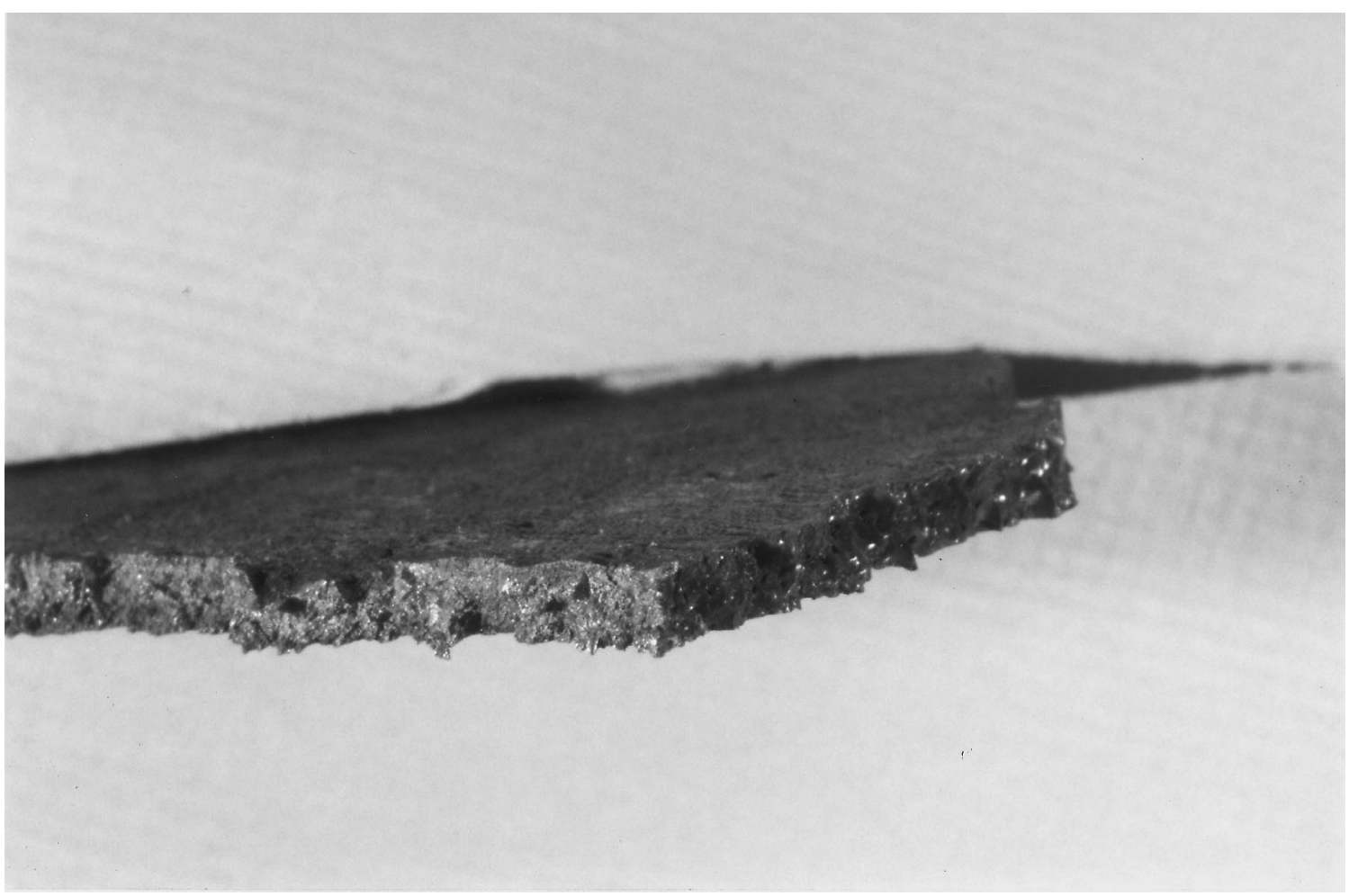

Fig. 4. Blue oxide layer on the fracture surface of a bronze impeller.

occurred within the coating. A micrograph showing that failure occurred within the coating and that some stellite is still adherent to the substrate at the point of coating failure is presented in Fig. 6. It is also clear from this micrograph that the stellite coating contains a large amount of porosity and oxide inclusions. When the amount of porosity and oxide inclusions reaches a certain critical value, which is

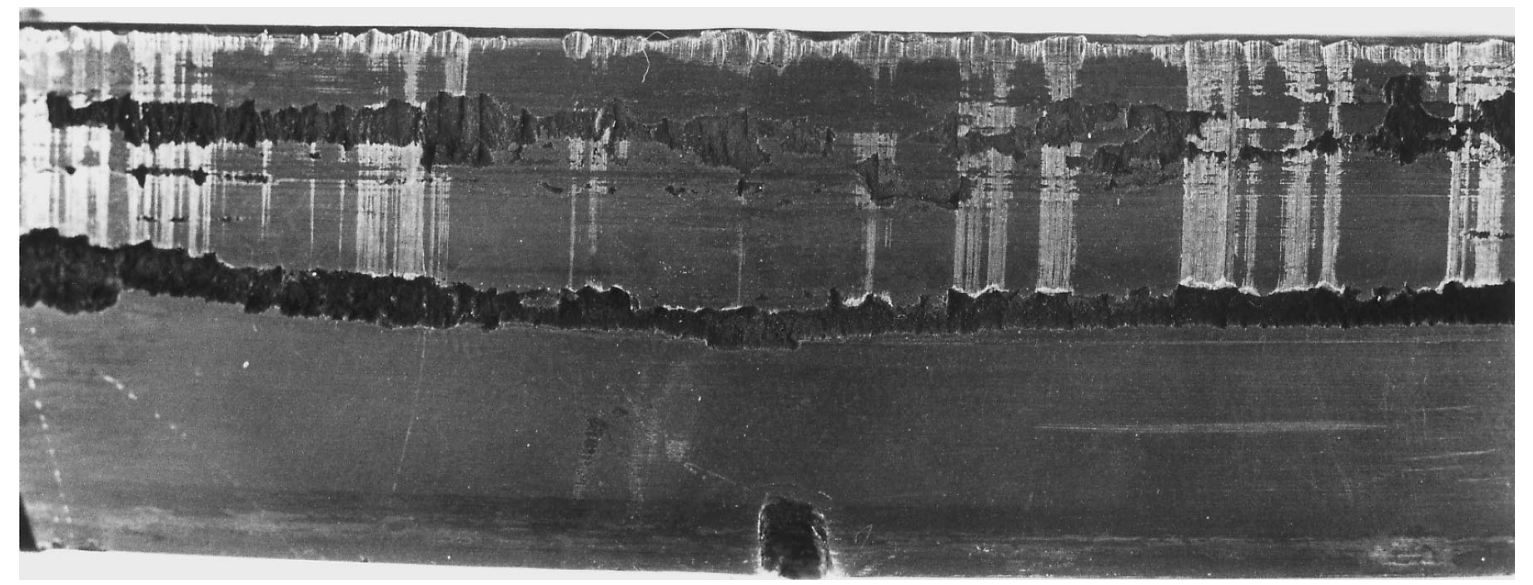

Fig. 5. Galling damage to a stellite-coated wear ring. 
dependent on the operating stresses and type of coating, disbonding and spalling of the coating will occur resulting in the damage observed in Fig. 5.

The specification of a $\mathrm{Ni}$ based, self-fluxing type of coating applied by powder flame spraying followed by fusing is correct, but it can be seen that some of the spraying parameters were not optimised resulting in an inferior coating. Once again, there is nothing that the operator of the pump could have done to prevent failure of this type other than to insist that proper quality control measures are implemented by the supplier of the pump components.

\section{Cavitation case study}

The following case study relates to the failure of a type CF-8M pump impeller by the mechanism of cavitation (see Fig. 7). This impeller was used to pump an acidic ( $\mathrm{pH} 2-3$ ) nickel sulphate solution at a flow rate of between 1300 and $2000 \mathrm{l} / \mathrm{min}$. The acid solution which was at a temperature of $20-30^{\circ} \mathrm{C}$, contained some precipitated crystals and had a general composition of: $6-10 \mathrm{~g} / \mathrm{H}_{2} \mathrm{SO}_{4}, 500 \mathrm{~g} / \mathrm{l}$ $\left(\mathrm{NH}_{4}\right)_{2} \mathrm{SO}_{4}, 0.1-0.2 \mathrm{~g} / 1 \mathrm{Ni}, 0.1-0.2 \mathrm{~g} / 1 \mathrm{Co}, 0.1-0.2 \mathrm{~g} / 1(\mathrm{Fe}+\mathrm{Mn}), 50-70 \mathrm{ppm} \mathrm{Cl}{ }^{-}$and 2-5 g/1 Na.

Examination of the impeller showed it to be extensively pitted, with the pitting damage being more severe at some locations than at others, (see Fig. 8). The distribution and appearance of the pits showed that failure was most likely due to cavitation.

Cavitation destroys the functional efficiency of the component and leads to high running and maintenance costs. It normally occurs at low pressure regions of rapidly vibrating liquid/metal interfaces. Where the local pressure in a liquid is reduced below the vapour pressure of the liquid without temperature change, a condition may be reached where bubbles/cavities nucleate and grow within the liquid body. The process of bubble formation is exceedingly rapid and is enhanced by turbulence (which can be caused by high flow rates or surface irregularities of the component).

Damage is caused when the bubbles make contact with the surface and collapse due to a localised

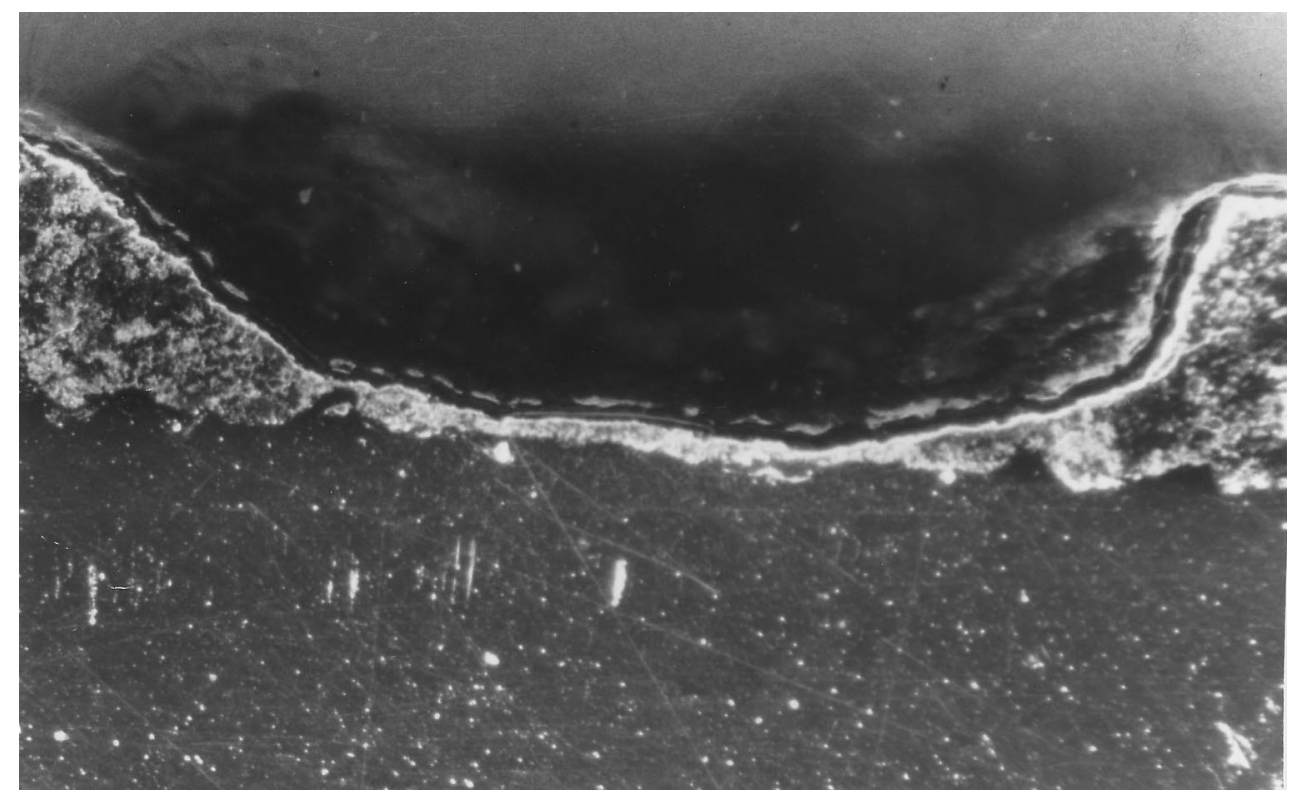

Fig. 6. Failure of stellite coating in wear ring of Fig. 5 revealed by metallographic sectioning. 


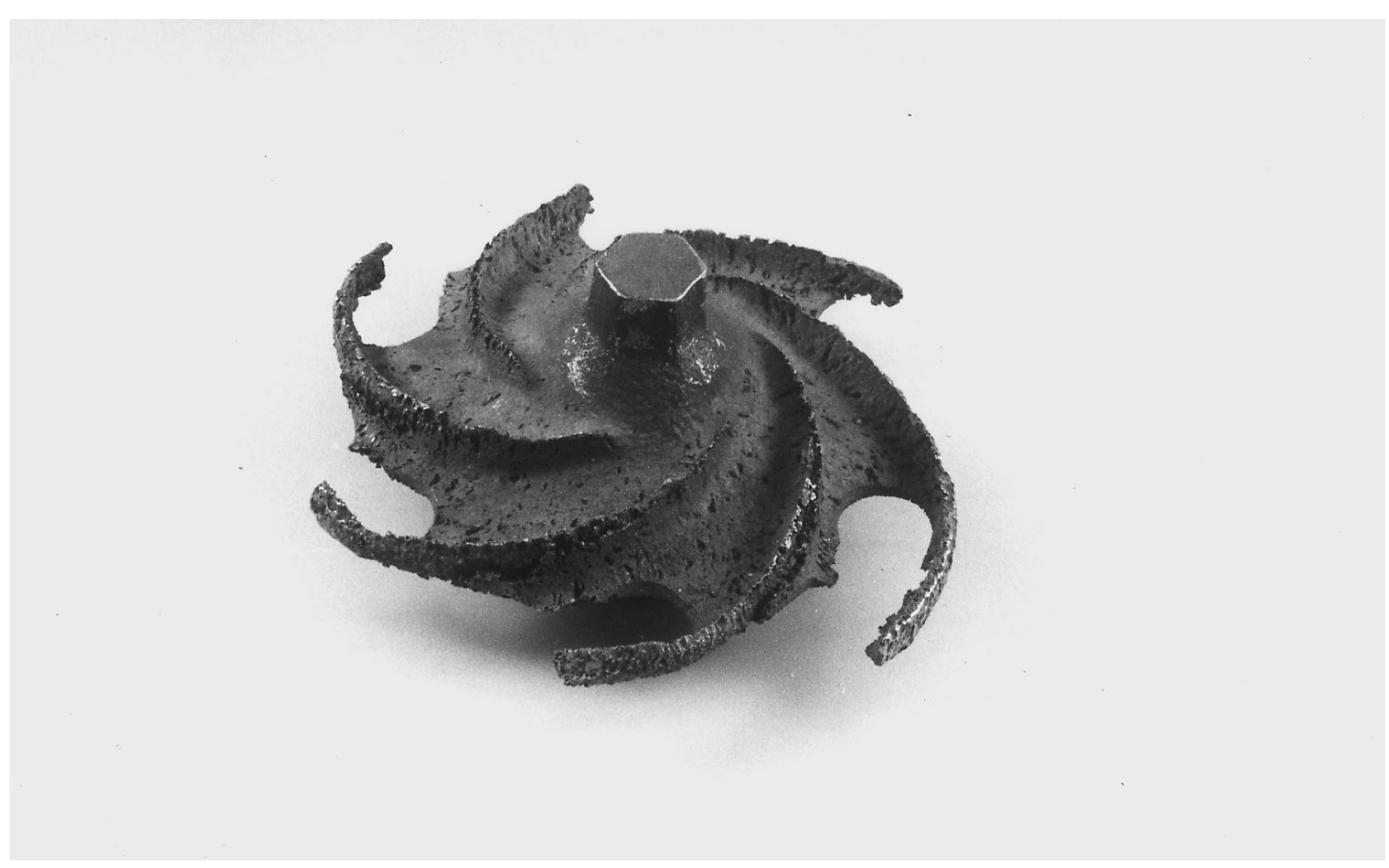

Fig. 7. Cavitation failure of cast 316 type stainless steel impeller.

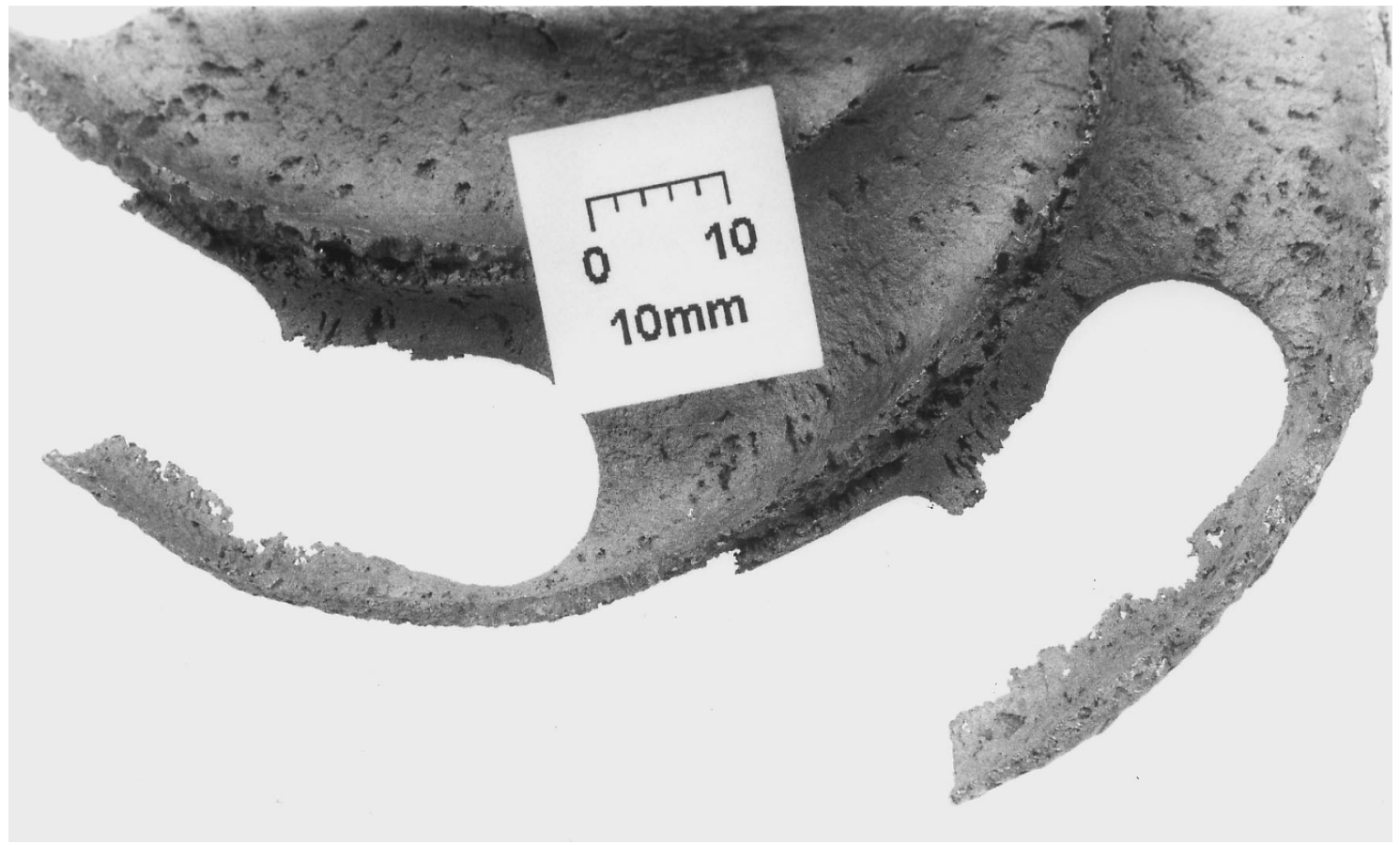

Fig. 8. Close-up of impeller of Fig. 7. 
increase in the pressure. This is why cavitation damage is often observed at the high pressure side of a pump (outlet) due to the bubbles collapsing under the influence of the higher pressures in this region. Repeated implosions of these bubbles are sufficient to cavitate the surface, especially if corrosion products are present. These implosions are so severe, resulting in stresses of $60,000 \mathrm{lb} / \mathrm{in}^{2}$. or about 400 $\mathrm{MPa}$ [1], that they can damage the passive film of stainless steels and even remove some surface material. It should also be noted that this stress is above the yield strengths of many materials and as such some localised plastic deformation could also be expected. The exact mechanism by which collapse of the bubbles transmits the localised force to the surface is not fully understood, but it is thought to involve shock waves produced by the collapsing bubble, and the immediate development of a new cavity [2].

Due to the high rate of formation and decay of cavities, damage is rapid [3]. Cavitation damage can be divided into four stages, namely:

Stage 1: bubbles form due to velocity or turbulence effects (pressure differences)

Stage 2: bubbles make contact with the material surface

Stage 3: bubbles implode on the surface, setting up shock waves thereby damaging or removing some surface material

Stage 4: repetition of the above process.

Although the presence of a corrosive environment enhances cavitation damage, it is not essential to the process. As far as predicting the resistance of a metal to cavitation damage, it appears as though the degree of degradation is related to the pitting resistance rather than the general corrosion resistance of the material [4]. The presence of pits on the surface of the impeller also causes disruption of the lamellar flow conditions and therefore tends to create turbulent flow which can lead to the creation of excess cavities/bubbles [4]. From this, it is evident that once cavitation has started, damage of the impeller will occur at an ever-increasing rate.

When an impeller operates in a corrosive environment, damage as a result of cavitation may be confirmed by the lack of corrosion products on the component's surface since these are removed by the cavitation process. Cavitation is also affected by the amount of entrained air and the presence of solid particles that can act as nucleation sites for cavity formation. In this case no corrosion products were observed on the surface of the impeller, again confirming that cavitation was the cause of failure.

Since the geometry of the pump and the properties of the liquid are relatively constant, the cavities will tend to form at preferred locations. With constant repetitive 'implosions' a pit is formed locally and degradation begins to accelerate. If the system has a stagnation period, a surface film may form in the pit, but this is normally rapidly removed under dynamic flow conditions and continued cavitation [5].

Cavitation can be controlled by the following methods:

- choice of materials

- hard-facing the surface of impellers to resist the effects of implosions

- using rubber or other linings to reflect shock waves without resulting in severe damage

- design to increase the pressure of the system or decrease the turbulence

- using inhibitors to increase vapour pressure of the liquid.

\section{Microbial/bacterial induced corrosion (MIC/BIC)}

When the media being pumped contains organic matter and nutrients, corrosion may be initiated or accelerated by the action of micro-organisms which promote corrosion by various mechanisms. In most 
cases it is the metabolic by-products such as organic and inorganic acids and hydrogen sulphide in addition to the effects of differential aeration cells that are formed beneath the tubercles that cause corrosion of pump impellers and housings (including the protective coatings in some cases).

MIC is particularly a problem in nearly neutral water especially when the water contains sulphur compounds and other organic nutrients.

Of the various organisms that promote corrosion, the best known are [6]:

\section{Biological name}

Desulfovibrio desulfuricans

Thiobacillus thiooxidans

\author{
Oxygen presence \\ (anaerobic) \\ (aerobic)
}

$$
\begin{aligned}
& \text { pH range } \\
& \text { pH 4-8 } \\
& \text { pH } 0.5-8
\end{aligned}
$$

\author{
Temperature range \\ $10-40^{\circ} \mathrm{C}$ \\ $10-40^{\circ} \mathrm{C}$
}

As can be seen from the conditions required for proliferation of these micro-organisms, colonisation of the metal surface can occur under both aerobic and anaerobic conditions. Corrosion by the anaerobic sulphate reducing bacteria, Desulfovibrio desulfuricans, can even proceed under aerobic conditions if tubercles are present. This is because the tubercles create a protective anaerobic environment in which the anaerobic bacteria can thrive.

Although some strains of corrosion-promoting bacteria can survive outside the ranges presented above, these are less common and are thus of less importance.

Since very low flow or stagnant conditions are required for colonisation of the bacteria, microbiologically influenced corrosion is seldom encountered in pump components. A recent failure has however been encountered where reduction in the demand for water has resulted in one of the pumps in the pump station being used for standby and during peak demand periods. In the interim, however, the pump is idle and contains stagnant water for a period up to several weeks. During this period sufficient time is available for microbial colonisation and corrosion to occur. In addition to pitting caused by the bacteria, examination of the pump impeller revealed some signs of early cavitation damage which was suspected to occur as a result of the tubercles, that form from bacterial colonisation, interfering with the flow characteristics and causing turbulent flow.

In situations like this, use of the pumps should be alternated to ensure that the pumps are not allowed to remain stationary for more than $24 \mathrm{~h}$. If this is done, then the formation of bacteria will be limited and thus microbially influenced corrosion of the pump components should also be limited.

\section{General corrosion}

General corrosion of pump components, especially impellers, usually occurs when the incorrect materials have been chosen for the specific application or when the service conditions in which the pump operates have changed. As the name would imply, general corrosion is the name given to the uniform removal of metal from the surface of a metallic component over a period of time. Since the corrosion is uniform, damage of this type manifests itself over a period of time and is usually detected by a gradual decline in pump efficiency. A photograph of a cast-iron pump impeller which has been removed from service due to general corrosion is presented in Fig. 9. It is clear from this photograph that the impeller has become significantly thinned due to general corrosion and that the pump efficiency would also have been unacceptable. This impeller was used to pump relatively low $\mathrm{pH}$ waters. Had a stainless steel or bronze impeller been used, no corrosion problems would have been experienced. It should also be noted that recent advances in coating technology have resulted in the formulation of several coatings that can be used to protect pump components by forming a physical barrier between the metal components and the media being pumped. 


\section{Wear and abrasion failures}

Many pump components fail in service because of a combination of corrosion and erosion. Erosioncorrosion accelerates the rate of attack because of relative movement between a corrosive fluid and the metal surface. Generally, this movement is quite rapid, and mechanical wear i.e. abrasion can be involved. Material is removed from the component's surface as dissolved ions, or in the form of solid corrosion products which are mechanically 'swept' from the component surface. Most pumps used in the mining and mineral processing industries pump slurries rather than pure liquids. These slurries consist of widely varying contents and the solids themselves vary in particle size depending on the stage of ore processing.

When the fluid velocity exceeds some critical value, the film of corrosion product on the substrate is stripped mechanically from it, and the rate of corrosion increases rapidly. Not only is the protective barrier lost, but the forced transfer of dissolved oxygen to the corroding surface accelerates the rate of corrosion even further.

Mechanical stripping of the film of corrosion product results from the transfer of kinetic energy from the fluid to the swept surface and when there are solid particles present in the fluid/slurry this can occur at much lower velocities. It should be noted that corrosion is not a necessary factor in producing this form of damage, but if a corrosive environment is present it could contribute to the severity of the damage.

The variables of the solid phase that affect the erosion-corrosion rate of a pump impeller are:

particle size and distribution

particle density

particle shape

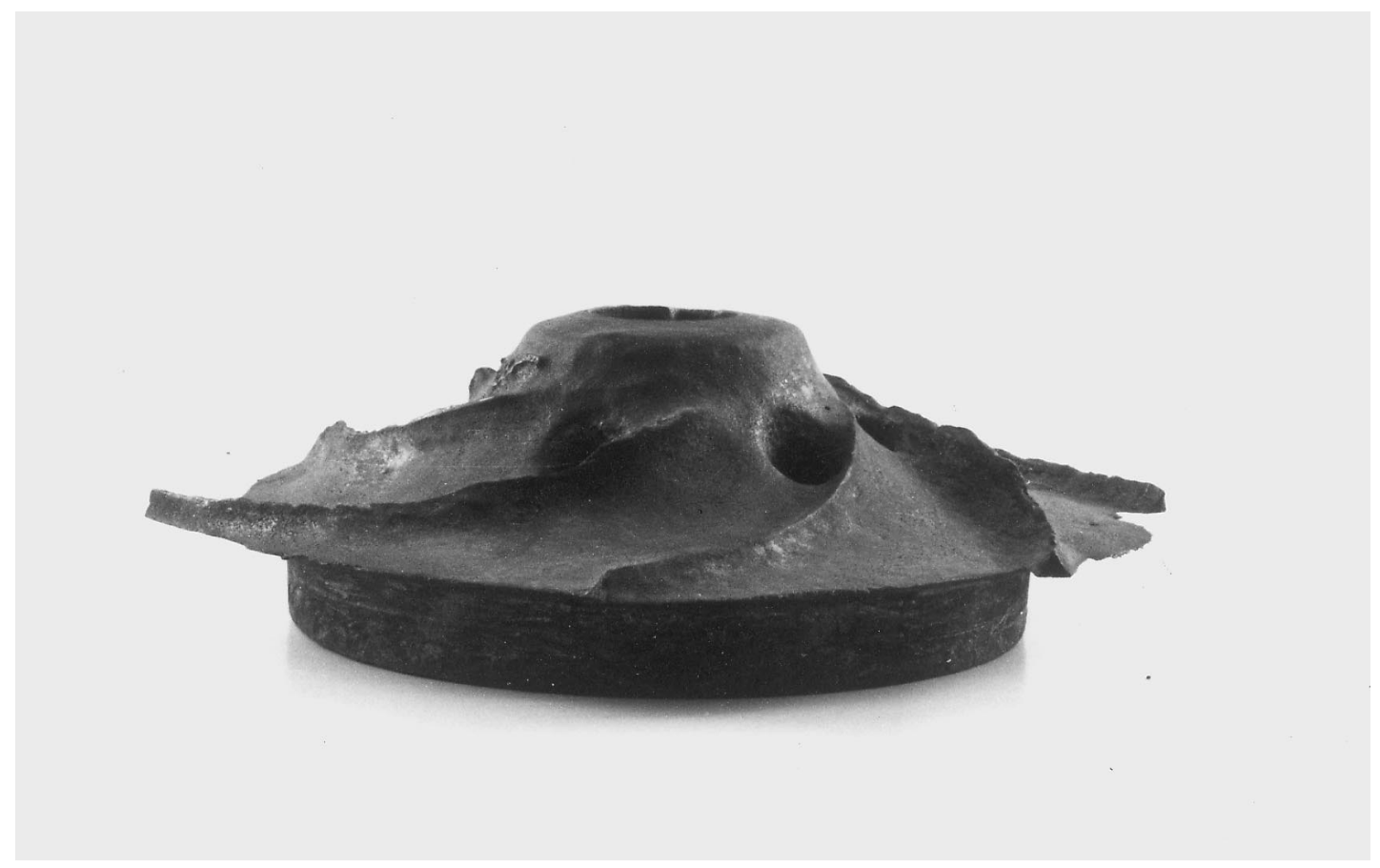

Fig. 9. General corrosion of a cast-iron impeller. 


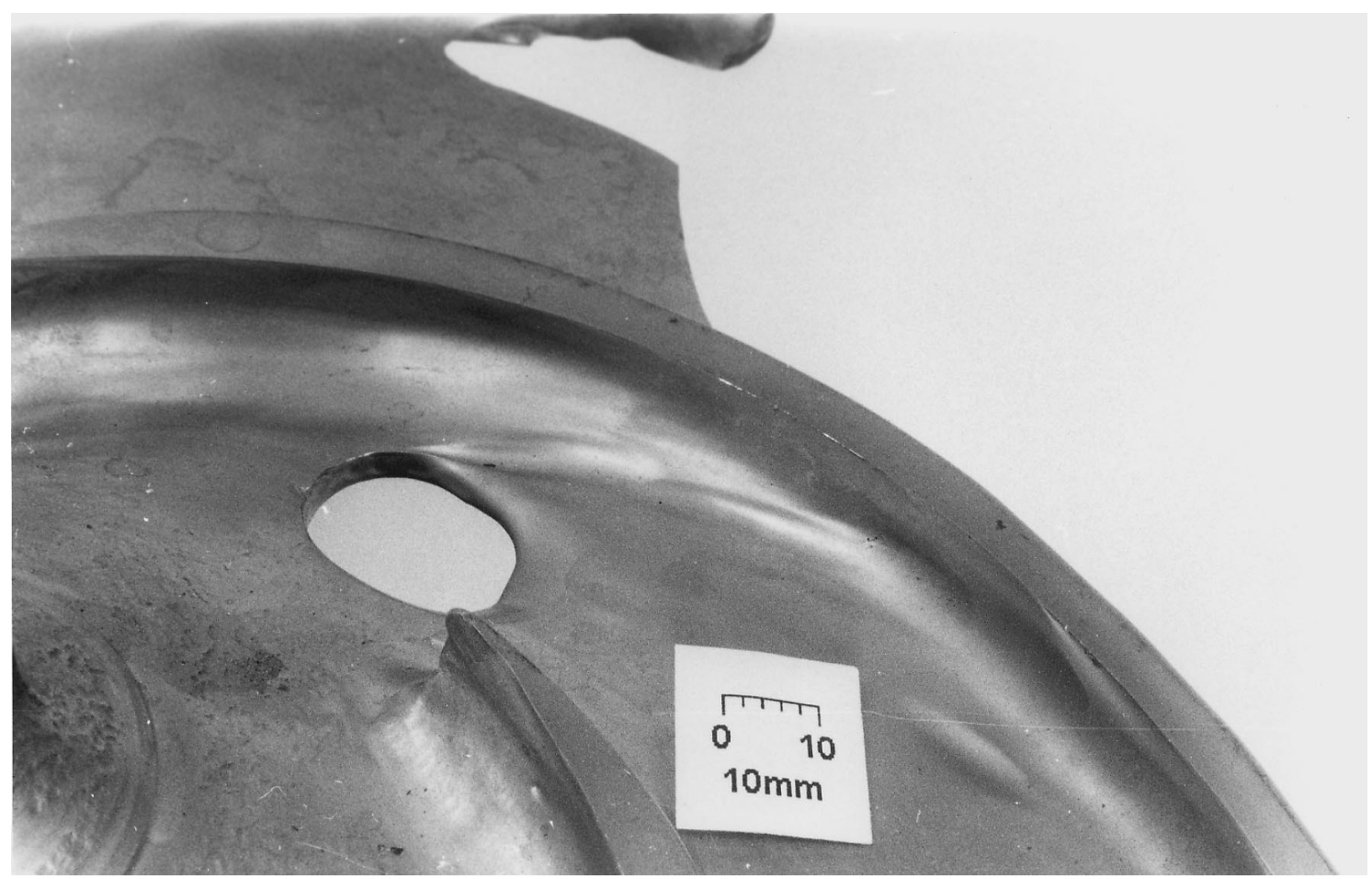

Fig. 10. Erosion-corrosion grooves and depressions on an impeller surface.

particle composition

concentration of solid in the slurry.

Variation in the rate of erosion with the concentration of solids in a slurry appears to follow a definite pattern. This is a linear increase in the rate of material damage with increasing concentration of solids up to a certain level, followed by a much slower rate of increase at higher concentration. Erosion-corrosion is characterised by the presence of grooves, as illustrated in Fig. 10, and holes on the surface of the metal, which usually exhibit a directional pattern.

Passive alloys, such as stainless steels, depend on the development of a tightly adhering surface oxide film for resistance to corrosion. In quiescent acids and acidic waters, these alloys may be resistant to attack. In flowing acids, however, operation at velocities above a certain critical level may destroy the passive layer, causing the alloy to become active and corrode rapidly. This velocity is referred to as the 'breakdown velocity'. Since the rate of corrosion in the active state can be orders of magnitude higher than in the passive state, the effect of erosion-corrosion can be very marked. Slurries containing particles denser than water will give rise to a lower breakdown velocity.

\section{References}

[1] Fontana MG. Corrosion engineering. 3rd ed. New York: McGraw-Hill, 1987 International Editions.

[2] American Society for Metals. Failure analysis and prevention. In: Metals handbook, vol. 11. 9th ed. Metals Park, OH: American Society for Metals, 1986.

[3] Colangelo VJ, Heiser FA. Analysis of metallurgical failures. New York: Wiley, 1974. 
[4] Godfrey DJ. In: Schreir LL, editor. Corrosion, vol. 1. New York: Wiley, 1963. p. 8.

[5] Wulpi DJ. Understanding how components fail. Metals Park, OH: AIM, 1985.

[6] Jones DA. Principles and prevention of corrosion. Maxwell MacMillan, 1992 International Editions. 